\title{
Assessment of purchasing contribution to the development and growth of SMEs, evidence from Tanzania
}

\section{Paul M. Nsimbila}

School of Business,

Department of Procurement and Logistics Management, Mzumbe University, P.O. Box 6, Mzumbe, Morogoro, Tanzania

E-mail: pmnsimbila@mzumbe.ac.tz

E-mail:pmnkabelele@yahoo.co.uk

\author{
Jan A. Jurriëns* \\ HAN University of Applied Sciences, \\ Ruitenberglaan 31, 6826 CC Arnhem, The Netherlands \\ E-mail: jan.jurriens@han.nl \\ E-mail: jan.jurriens@planet.nl \\ *Corresponding author
}

\begin{abstract}
The contribution of purchasing to the development and growth of small- and medium-sized enterprises (SMEs) and the overall performance of supply chain has been neither rigorously examined nor empirically substantiated. This paper provides empirical evidence on how purchasing variables (relationship, product quality and quantity, and price) contribute to the development and growth of SMEs in Tanzania. In this study, it was found that poor relationships between suppliers and SMEs and low quality of products sold by SMEs affect the provision of service to customers and lead to poor development and growth of SMEs while high prices of products and low quantity of goods have no direct effect. Conclusions drawn include: SMEs can improve the supplier relationship, e.g., by finding alternative product sources at low prices but not at the expense of quality, and by ordering the products from suppliers on time to avoid late delivery and stock depletion.
\end{abstract}

Keywords: development; growth; procurement; purchasing; small- and medium-sized enterprise; SME; supply management; Tanzania.

Reference to this paper should be made as follows: Nsimbila, P.M. and Jurriëns, J.A. (2012) 'Assessment of purchasing contribution to the development and growth of SMEs, evidence from Tanzania', Int. J. Entrepreneurship and Small Business, Vol. 17, No. 1, pp.27-43.

Biographical notes: Paul M. Nsimbila is a Lecturer at Mzumbe University, Tanzania. He received his MSc in Purchasing and Logistics at Salford University of Greater Manchester, UK. He studied advanced diploma in materials management at Mzumbe University and has a Certified Procurement and Supplies professional degree offered by the National Board of Materials Management (NBMM) of Tanzania. He is an External Examiner of various high learning institutions in Tanzania. His specialisation is in the areas of 
procurement, contract management and supply chain management. His main research interests are in the area of purchasing, supply chain management and SMEs development.

Jan A. Jurriëns is a Professor at HAN University of Applied Sciences in the area of logistics, cooperation and network. He participates in the Boards of Supervisors of Hospital and Housing Association. He is also a member of the board of examiners Warehouse Skills of the National Logistics council. He was a senior partner of the Twynstra Group. He specialises in translating strategies, business development, sourcing, alliances, supply chain management and support management. He studied logistics at Transport Academy in Tilbury and Business Administration at the Erasmus University in Rotterdam. He received his PhD degree at Nijenrode University in Breukelen.

\section{Introduction}

Tanzania is one of the developing countries in East Africa. Its major growing economic activities include mining, manufacturing, fishing, tourism and agriculture. Most of those activities employ people in small and medium enterprises (SMEs). Those involve mostly which employ many people in SMEs. SMEs can be easily established in Tanzania since their requirements in terms of capital, technology, management and even utilities are not as demanding as they are for large enterprises. Because of their large numbers, SMEs are increasingly being recognised as playing a crucial role in creating employment and generating income in the country (URT, 2003; Lisotchkina, 2006; Manoilova, 2006). However, the full potential of the Tanzanian SME sector has yet to be tapped due to several constraints hampering the sector's development, including an unfavourable legal and regulatory framework, undeveloped infrastructure, poor business development services, limited access of SMEs to finance, and an ineffective and poorly coordinated institutional support framework (URT, 2003).

To grow well, SMEs need a well-developed and well-coordinated supply chain since this enables a smooth flow of products to the customer. Most studies on supply chain management (SCM) investigate the flow of goods of large firms. Those studies that investigate small firms mostly do so from the viewpoint of larger firms with a minor attention to purchasing (Lambert and Cooper, 2000). Most studies on SCM investigate the flow of goods of large firms, while small firms are treated mostly from the viewpoint of larger firms with minor attention to purchasing (Lambert and Cooper, 2000). Quayle and Quayle (2000) found that the SCM of many SMEs has received little attention from owner-managers. In fact, managers ranked SCM 14 out of 19 attributes valued by them when managing their firms. This low ranking is striking considering that SCM is integral to the good performance of SME's.

To understand the importance of this relationship, more studies are needed to qualify the impact of SCM on the growth development of SME's. This study, therefore, investigated the contribution of SCM to the growth development of SMEs in Tanzania.

Since SMEs are found in manufacturing, mining, commerce, and service industries, this investigation concentrates on SMEs involved in the retail business of buying products/commodities from suppliers (manufacturers, wholesalers and distributors) and reselling them to end users/consumers. Both formal (registered) and informal 
(unregistered) SMEs were researched in this study for a total of 104 micro enterprises, 42 small enterprises and 16 medium enterprises.

\section{Meaning of the SMEs in Tanzania}

Every year about 700,000 new workers enter the labour force in Tanzania. About 500,000 of these are school leavers with few marketable skills. The public sector employs only about 40,000 of these new labourers, while about 660,000 join the unemployed or the underemployed reserve. Most of these 660,000 people work in the SME sector, especially in the informal sector. Given this situation and the fact that Tanzania is characterised by a low rate of capital formation, SMEs are the best option to address unemployment and underemployment reserve this problem (URT, 2003). In Tanzania, SMEs include micro as well as SME. Micro enterprises are enterprises engaging up to four people or employing capital of up to US\$5,000. Small enterprises have five to 49 employees or capital of US\$5,000 to 200,000. Medium enterprises employ 50 to 99 people or use capital investment from US\$200,000 to US\$800,000. The SMEs cover non-farm economic activities, especially manufacturing, mining, commerce and services (URT, 2003).

\section{Meaning of the supply chain and especially purchasing and a relationship}

A supply chain or logistics network is a system of organisations, people, technology, activities, information and resources involved in moving a product or service from supplier to customer. Supply chain activities transform natural resources, raw materials and components into a finished product that is delivered to the end customer. Supply chains can be described as business networks (Merminod et al., 2007). Van der Vorst (2004) describes a supply chain as a set of sequential, vertically-organised transactions that create value in phases (Figure 1). Sequential, vertically-organised also means purchasing from each other. According to Dobler and Burt (1997), purchasing is the process undertaken by the organisational unit that, either as a function or as part of an integrated supply chain, is responsible for procuring or assisting users to procure required supplies in the most efficient manner as well as at the right time, quantity and price and from suppliers. As such, purchasing contributes to the competitive advantage of the enterprise and the achievement of its corporate strategy. Players/actors in the supply chain depend on the type of business. In most cases, at least three to seven players participate in a chain that may include but is not limited to first tier suppliers (Figure 2). These first tier suppliers are producers of income goods or raw materials, processors, distributors, retailers and consumers. Each of these players has his own powers depending on the supply and demand in the market place and each focuses on SMEs that are found in the retail branch. The growth and profitability of these players might depend on the upstream players in the supply chain, which is the supply side, or on the downstream players in the supply chain, which is the demand side. However, the growth and profitability may also be affected by internal processes and transformation of inputs from the supply side to outputs that will be sold to the demand side. 
Figure 1 A smart supply chain (see online version for colours)

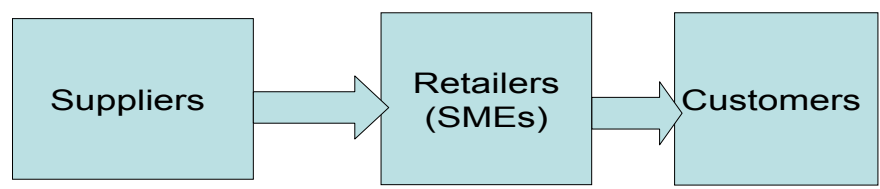

Figure 2 The automotive supply chain (see online version for colours)

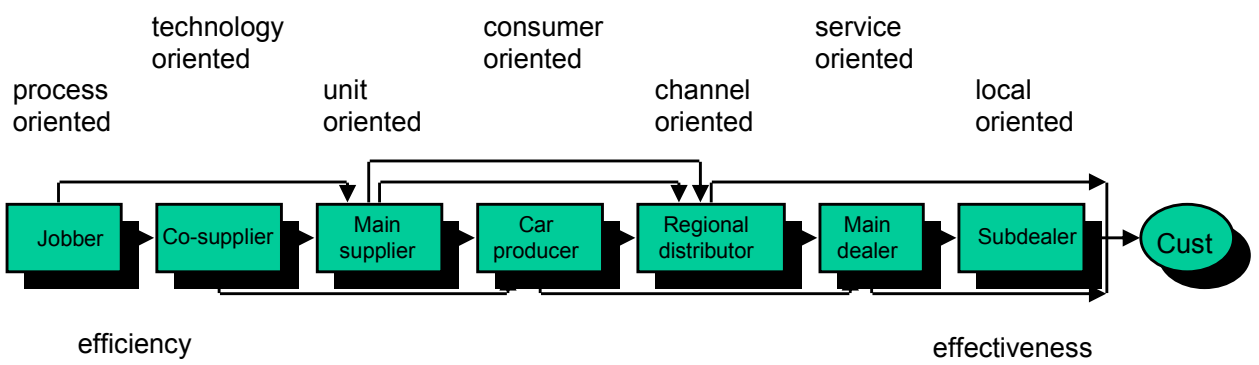

In 1997, a paradigm shift was recognised from purchasing based on a transaction way of thinking to purchasing based on a longer-term relationship between a buyer and a supplier (Seth and Sharma, 1997). This type of purchasing focuses not only on the lowest price but also on a long-term relationship. Parallels can be recognised in the development from purchasing as an accountable function to purchasing more as a conductor of a supply chain/network (Andersen and Christensen, 2005). For Tanzania, in particular, this is an important aspect. Long distances make the delivery of the good a tricky business. It is thus a win-win situation for the nodes in the supply chain and essential for the growth of the SME's. Thus, a win-win situation for the nodes in the supply chain, a tricky business and thus essential for the growth of the SMEs.

\section{Relationship}

The relation between the nodes in the chain is an important aspect, but which relationship is important? According to Crocker and Emmett (2006), and Duister et al. (2004), the supply chain is characterised by four types of relationships: adversarial, preferred, collaborative and strategic. An adversarial relationship is short-term and confrontational, and associated with win-lose negotiations and retention of information. In this type of relationship, purchaser's multisource, negotiate short-term contracts, maintain secrecy regarding costs, sales and product design, and they neither make nor receive improvement suggestions to or from suppliers. For this reason, they have many suppliers.

Preferred suppliers have win-win supplier-buyer relationships. These suppliers are providers of complementary goods and services of medium asset specificity or strategic importance. Preferred suppliers have been placed by the purchaser on a restricted list of potential suppliers after a process of vendor rating and accreditation. Under this type of buyer-supplier relationship, suppliers may be eliminated from the list whenever their performance is unsatisfactory. Due to variability in relationships, buyers have to maintain a high supplier base as security so that if one supplier fails to supply the required item, the buyers will have other suppliers who can. 
A collaborative relationship is a long-term partnership with win-win negotiations and information sharing. The supplier base under this type of relationship is low because few suppliers are maintained. Moreover, Crocker and Emmett (2006) argue that a collaborative relationship is a formal relationship between two or more parties to pursue a set of agreed upon goals or to meet a critical business need while remaining independent organisations. Partners may provide the strategic alliance with resources such as products, distribution channels, manufacturing capability, project funding, capital equipment, knowledge, expertise, or intellectual property.

The alliance is cooperation or collaboration that aims for a synergy where each partner hopes that the benefits from the alliance will be greater than those from their individual efforts. In short, a collaborative relationship seeks to establish a good relationship between suppliers and SMEs so that the SME can provide better service.

Finally, the negative relationship (adversarial, etc.) negatively affect SME's while collaborative ones positively influence SME. That is in line with socio-economic research. Relationships in networks represent a means for entrepreneurs to reduce risks and transaction costs and to improve access to business ideas, knowledge, and capital. A social network consists of a series of formal and informal ties between the central actor and other actors in a circle of acquaintances. As such, we hypothesise that a good relationship between SMEs and other actors in the supply chain results in better customer services (no. 1).

\section{The products, the prices and place}

While quality in the relationship between partners is an important aspect of a business relationship, it is not as important as quality of the product. Quality of the product means excellence: the degree to which a product satisfies the wants of a customer or the whole set of features and characteristics that are relevant to meet customer requirements. The right quality is defined in terms of fitness for purpose; it is that which meets the customer's need//it is that which meets the customer's demand. To produce products of the right quality, manufacturers need to have advanced production tools and good inputs (raw materials) (Fung, 1999). Baily et al. (2005) argued that a worsening of supply quality increases the variability of the supply of components available to firm. Quality affects the lead time taken by the supplier. When the quality of the delivered goods does not meet the quality specified in the contract, goods need to be replaced. Replacement time of the goods is important. As a result, the firm will often have to carry more safety inventory often from a low quality supplier. The component quality also impacts customer satisfaction and product cost because of rework, lost materials and the cost of inspection. Baily et al. (2005) concluded that possible causes of low quality of products can include both poor production tools and the inadequate selection of raw materials for manufacturing firms. Olomi (2006) found that SMEs in Tanzania are unable to effectively start up and/or to substantially grow quantitatively for various reasons including the inability to access loan financing and markets, use of obsolete technology and weak support infrastructure. All these factors result in poor quality products and/or higher production costs that make a business uncompetitive and limit good growth and development. Therefore, we hypothesise that poor quality of products sold by SMEs are caused by poor productions tools and obsolete manufacturing technology (no. 2). 
Another aspect for a good relation between the participants in the chain is a fair price for the goods. However, this price is not necessarily the lowest price. It is the price that brings the best ultimate value invested in purchasing the materials. Thus, price may be defined as the sum or amount of money that a seller sets for his goods in the market, while the purchase price is the value of goods and services asked for and paid in monetary terms. The purchaser pays for the value of goods and services, but this value may not be the lowest price of//for? the goods (Lysons and Gillingham, 2003; Dobler and Burt, 1997). De Boer et al. (2003) argued that in determining the purchase price, the intending purchaser considers the following three points. First, the price is right for the purchaser if the consignment is not expected to be delayed. Second, if the standard of service is normal, the specification is adhered to, the instructions are strictly followed, the adjustments, if any, are made as and when required. Third, the suppliers/sellers consider the purchase prices of products when setting selling prices of products to be sold to SMEs. Their purchase prices include the products' list prices plus transportation costs. The higher the purchase prices paid by suppliers when acquiring the raw materials/goods, the higher the selling prices of products to SMEs and vice versa. Therefore, we hypothesise that high prices of products/commodities sold by SMEs are mainly caused by high prices of raw materials/finished goods (no. 3).

The last aspect for a good relation between the participants in the chain is the place of the product, in this situation translated as customer services. Porter (1985) defines the customer service level as the level of satisfaction that a company is able to give to its customers. In its simplest form, the customer service level may be determined by taking the percentage of requisitions whose demand is met over the year. The customer service level shows the extent to which an organisation is able to meet the demands of its customers. However, the ability to meet customer demands depends on stock availability. High stock in this case will mean high customer service and vice versa for a low stock level. On the other hand, a high stock level for an SME means that the SME must have enough capital to buy a large amount of inventory. However, limited access to finance or capital markets is one of the factors that constrains many SMEs in Tanzania and in many countries (Aikaeli, 2007; Indarti and Langenberg, 2004). This aspect is important to Tanzania because the infrastructure is not at the European level. Therefore, we hypothesise that the availability of capital is crucial to having enough products to satisfy customers (no. 4).

\section{Conceptual and analytical framework}

Within goods flow, the term supply (or demand) chain management (SCM) is used (Bowersox and Closs, 1996; Van der Veen and Robben, 1999). SCM includes value chain entities upstream (e.g., supply and manufacturing) and downstream (e.g., logistics and distribution). Successful SCM requires integrating these value chain entities to create cooperative and collaborative environments that facilitate information exchanges, materials and cash flows (Kukalis, 1989).

Thus, a well-coordinated SCM creates the smooth flow of quality inputs and outputs at the right time from the right source and that will be delivered to the right place and at the right price (Lysons and Farrington, 2006). To achieve a well-coordinated supply chain, organisations are willing to buy or cooperate with parties in the chain. For this 
reason, purchasing has become more important in the supply chain. Hence, the definition of SCM includes aspects, such as quality in- and outputs (products) that will be delivered to the right place (place), in the right quantity and at the right prices (Lysons and Farrington, 2006; Porter, 1985) and promotion. Promotion is then related to the relationship of the nodes in the chain. Knowing this, we came out with the conceptual framework that guided us in the research process. The four P's are essential for a good profitable business and a satisfied customer. But, what relationship is the best one for an SME's supply chain in Tanzania and which aspects influence the other P's? (Figure 3 gives these aspects in a framework).

Figure 3 Conceptual framework (see online version for colours)

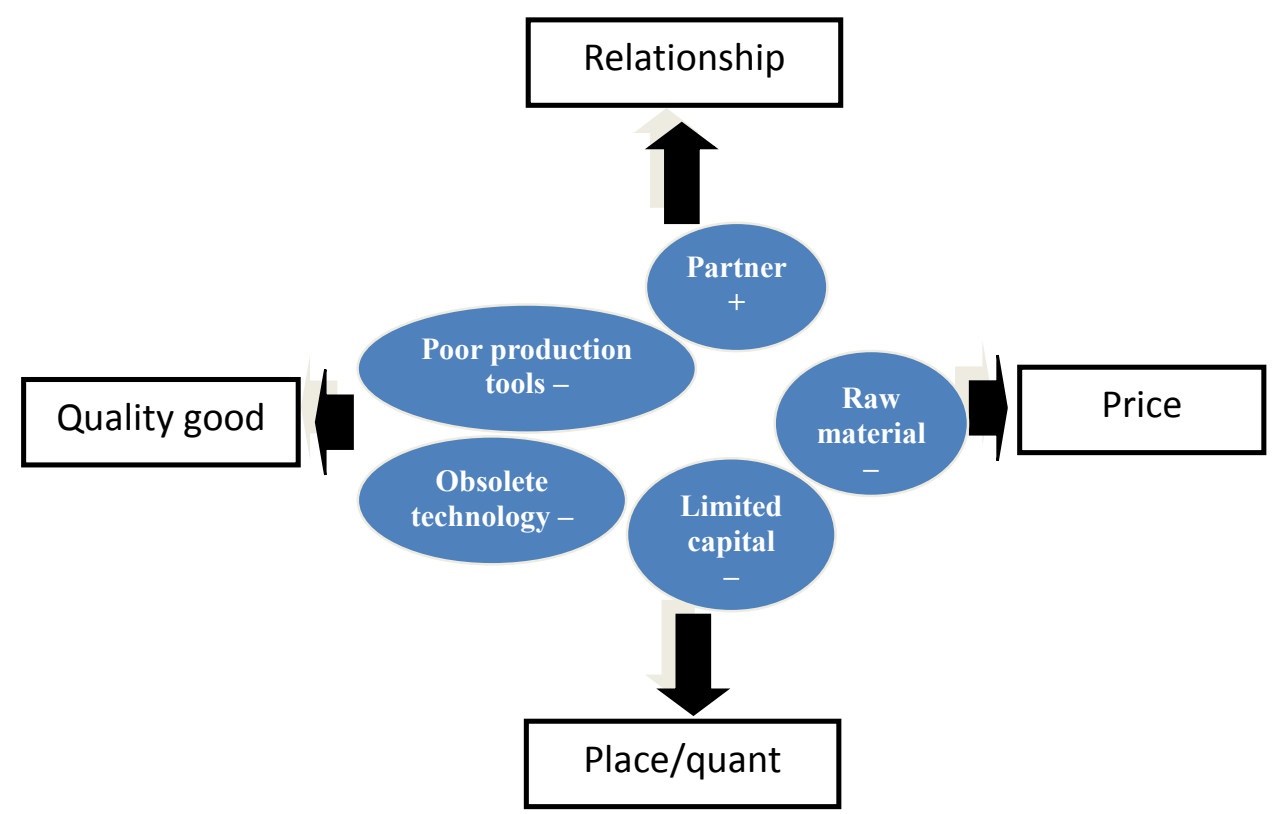

\section{$7 \quad$ Area of study and methods of data analysis}

The research was conducted in three regions of the Tanzanian mainland: Morogoro, Dodoma and Dar es Salaam. We chose these regions because of their production of agriculture products, the most important business of Tanzania. In Morogoro, SMEs buy goods and sell them to end customers and is an industrial region that produces many domestic products. SMEs buy these products and sell them to end users. Dar es Salaam, including its harbour and international airport, was chosen because it is the largest industrial and highly populated region where several SMEs trade different products. It is also the centre of imported goods for Tanzania. The Dodoma region was selected because it is a poor and dry region with seasonal agricultural activities and where people depend on buying goods from the SMEs to survive. Due to characteristics of these regions, they are representative of all 26 regions in Tanzania. 


\section{Data collection}

First, data were gathered using a documentary review approach. Next, different documents involved in delivery of goods, inspection of goods, ordering of goods were read and examined. These documents were reports, records, purchase receipts, sales receipts, purchase orders, inspection reports and other related materials or documents that enabled the researcher to confirm the correctness of information given in questionnaires.

Three methods of data collection were used for this survey to answer the hypothesis. The first method of data collection was the questionnaire with closed and open-ended questions. This method was used to collect general and some more specific information from the different SMEs. In our study, 210 questionnaires, 70 in each region, were distributed. From these 210 questionnaires, respondents returned 162. We distributed 70 questionnaires in each region with the aim of receiving at least 50 returned. In addition to the questionnaire and documentary review, the third method was in-depth interview. Twelve (12) entrepreneurs were interviewed in depth. The interviewees were randomly selected from the 162 respondents who filled in the questionnaires.

The in-depth interviews were carried out to gather more information on variables under the study. The total response to the questionnaire was high with a score of 77.14. The regional response was also high with Morogore scoring 81.43, Dodoma 71.43 and Dar es Salaam 78.57. The high response rate of questionnaires is due to the fact that the researcher and research assistants personally administered the questionnaires in all three regions. Table 1 shows the number of questionnaires distributed and filled in and the corresponding percentage of response.

Table 1 Sample size

\begin{tabular}{lccc}
\hline Region & $\begin{array}{c}\text { No. of questionnaires } \\
\text { distributed to SMEs }\end{array}$ & $\begin{array}{c}\text { No. of questionnaires } \\
\text { filled out by SMEs }\end{array}$ & \% of response \\
\hline Morogoro & 70 & 57 & 81.43 \\
Dodoma & 70 & 50 & 71.43 \\
DSM & 70 & 55 & 78.57 \\
\hline Total & 210 & 162 & 77.14 \\
\hline
\end{tabular}

\section{Analysis of data}

Easterby-Smith et al. (1991) argue that the prime purpose of data analysis is to assimilate evidence to provide answers to research hypotheses. In this study, data obtained through interviews were analysed qualitatively. However, data that were collected through questionnaires were analysed by quantitative methods, especially using Statistical Package for Social Sciences (SPSS). Explanations, descriptions, tables, percentages and frequencies have been used broadly in presenting results. Statistical measures including mean, standard deviation, variances, and chi-square have been used because we had enough response and answer to justify the values of such measures. 


\section{Findings}

From 162 entrepreneurs, 38 of them say that they have an adversarial relationship (win-lose relationship) with suppliers, 105 of them have a preferred relationship (win-win relationship), 34 of them have a partnership relationship and 23 of them have strategic alliance. Table 2 summarises the information on the relationship between SMEs (retailers) and other players in the supply chain. The entrepreneurs added that by having good relationships with other actors in the supply chain, entrepreneurs receive advantages of ensured supply of materials, ensured delivery of goods, better prices for products, and business promotion, all of which lead to better customer services. In some cases, the entrepreneur-supplier relationship is so good that entrepreneurs loaned products. This losan enables SME's to maintain better customer relations. This was supported//confirmed by $101 \mathrm{SMEs}$ in the preferred relationship and all SMEs in a partnership and strategic alliance relationship after cross tabulation. In contrast, 36 SMEs with a poor supplier relationship admitted that their development and growth are affected by not having a good relationship with suppliers (Table 3). These SMEs are not assured of good quality products, of the right quantity, and of the right time and price. Hence, they have to move to new supply chains where they start a new relationship of buying products in order to continue selling to end customers. It can be concluded that a good relationship between SMEs and other players in the supply chain results in better customer services because the quality of goods and services is better while an adversarial relationship results in poor quality of goods and poor customer service. This was further tested using a chi-square test and the results were chi-square $=130.993$, $\mathrm{p}$-value $=0 \%<$ $\alpha=5 \%$ means significant relationship. The chi-square is ordinarily high and the $p$-value very low, indicating a strong/significant relationship. This means that a win-win relationship always gives a high contribution to the buyer and a win-lose relationship never contributes. Based on these results, our first hypothesis is true.

Table 2 Relationship between SMEs (retailers) and other players in the supply chain

\begin{tabular}{lcccc}
\hline & Frequency & Percent & Valid percent & Cumulative percent \\
\hline $\begin{array}{l}\text { Adversarial relationship } \\
\text { (win-lose) }\end{array}$ & 38 & 23.5 & 23.5 & 23.5 \\
$\begin{array}{l}\text { Preferred relationship } \\
\text { (win-win) }\end{array}$ & 105 & 64.8 & 64.8 & 88.3 \\
$\begin{array}{l}\text { Partnership } \\
\text { Strategic alliance }\end{array}$ & 14 & 8.6 & 8.6 & 96.9 \\
\hline Total & 5 & 3.1 & 3.1 & 100.0 \\
\hline
\end{tabular}

Table 3 Contribution toward development and growth of SME by network members

\begin{tabular}{lccc}
\hline & Contribution yes & Contribution no & Total \\
\hline Adversarial relationship (win-lose) & $2(5.3 \%)$ & $36(94.7 \%)$ & $38(100 \%)$ \\
Preferred relationship (win-win) & $120(96.8 \%)$ & $4(3.2 \%)$ & $124(100 \%)$ \\
\hline Total & $122(75.3 \%)$ & $40(24.7 \%)$ & $162(100 \%)$ \\
\hline
\end{tabular}

Next, the researchers wanted to know if the quality of goods sold by SMEs was high or low and who along the supply chain determines the quality of such goods. The 
interviewees responded that some of the products sold by SMEs are of low quality and others are of good quality. When entrepreneurs were asked which nodes/actors in the supply chain determine the quality of products/commodities, 74 of them responded the manufacturers, 57 said the distributors, ten pointed to the wholesalers and 21 entrepreneurs stated the local farmers. Even though manufacturers, wholesalers, distributors and local farmers determine the quality of products sold by entrepreneurs, SMEs identified the following factors as adversely affecting the quality of products. These factors include poor production tool/facilities and hardware. Sixty-eight entrepreneurs commented that production facilities used to manufacture domestic products are poor and obsolete and consequently the outputs produced by those facilities are of poor quality. Entrepreneurs also mentioned that poor warehousing management and administration problems (85 responses), poor ICT such as the use of robots and modern computerised system (seven responses) and poor production processes (two responses) cause low quality products sold by SMEs. The factors affecting the quality of products bought and sold are summarised in Table 4. In short, although there are four factors that adversely affect the quality of products bought and sold by SMEs, two of these, warehousing management and administration $(52.50 \%)$ and poor production tool $(42 \%)$, are the major factors that greatly contribute to low quality goods in the supply chain. In contrast, ICT and poor production processes have little impact. Further, a statistical test gave a chi-square $=6,430, \mathrm{p}$-value $=4.0 \%<\alpha=5 \%$. These tables represent a significant relationship. A low chi-square and a high p-value mean a significant relationship. Customers are significantly different from the manufacturers and wholesalers/distributors (Table 5).

Table 4 Summary of factors that affect the quality of products bought/sold by SMEs

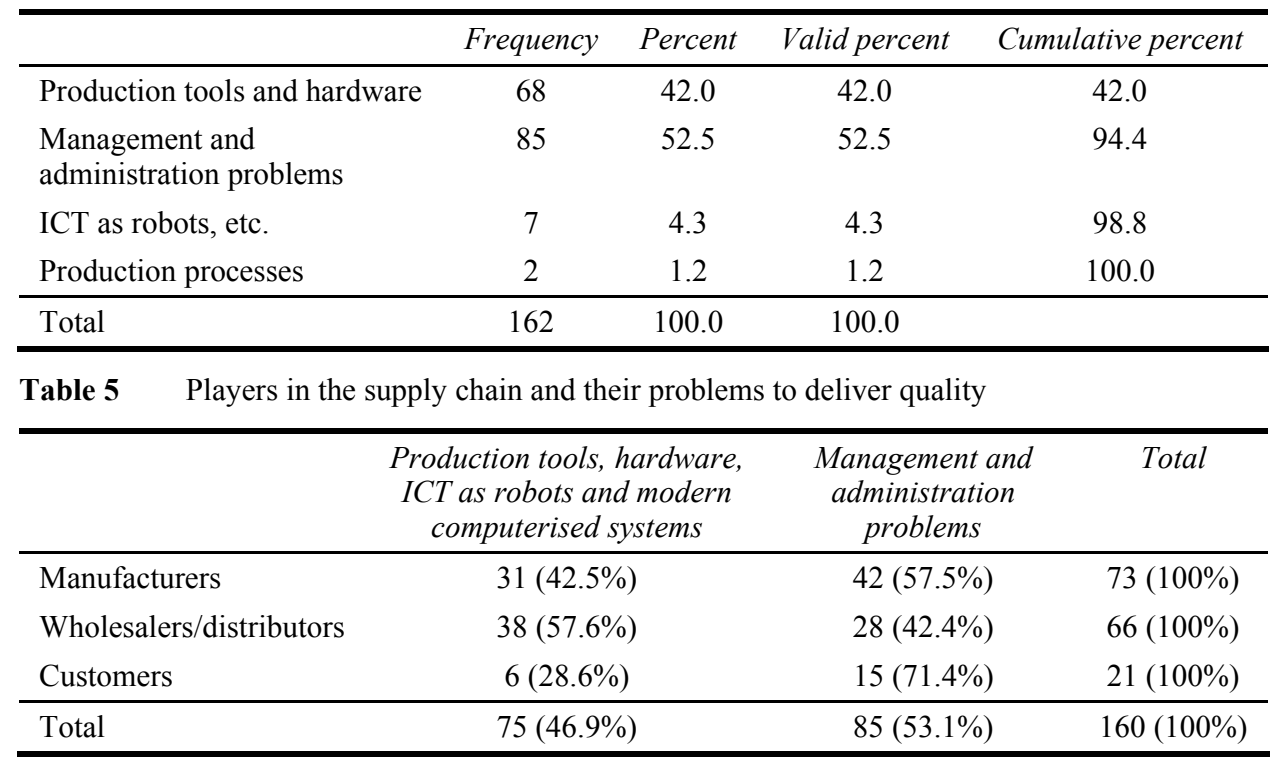

Under price variable of purchasing contribution to the development and growth of SMEs, the researchers were interested in knowing if high prices of products sold by SMEs are caused by high prices of raw materials/products from suppliers. High prices to customers mean that what they pay for a product does not match and is lower than the expected 
value. Entrepreneurs have identified many factors that increase the selling price of their products/commodities to end users. These factors include high purchase price of commodities/products from suppliers, high cost of labour, high cost of overheads (such as electricity, rent and rates) and variable and fixed costs. Moreover, it was revealed that market conditions dictate the selling price of products. Thus, supply and demand in the market place under perfect (pure) competition determine the selling prices of products. Under this condition, neither the buyers nor the sellers determine the selling price of products but the powers of supply and demand. As a result, many customers are not willing to purchase products at higher prices and entrepreneurs are forced to drop their prices and set new prices affordable to their customers. Entrepreneurs sometimes even have to dispose of their products at buying prices. This practice prevents them from making profit and results in poor development. In Table 6, the factors affecting the price of products bought and sold by SMEs are summarised.

After cross tabulation of the supply chain nodes that determine prices of products and the factors that affect the selling prices of products (Table 7), it was revealed that no significant relationship exists between them. This was proved by a chi-square test where. Chi-square $=7,461, \mathrm{p}$-value $=11.3 \%>\alpha=5 \%$. This means a low chi-square and a high p-value, which together indicate that there is no significant difference between manufacturers, distributors and wholesalers on how high prices of materials/products and overheads affect their selling prices.

Consequently, while SMEs have identified four factors that cause high purchase prices of materials from suppliers, two factors: high cost of labour and overhead costs have been identified as causing high prices of products/commodities sold by SMEs. Even though other factors do influence SMEs and their prices, these factors have such a low impact that they do not affect the way actors in the supply chain set their selling prices. Our hypothesis is neglected.

Table 6 Summary of factors that affect the price of products bought/sold by SMEs

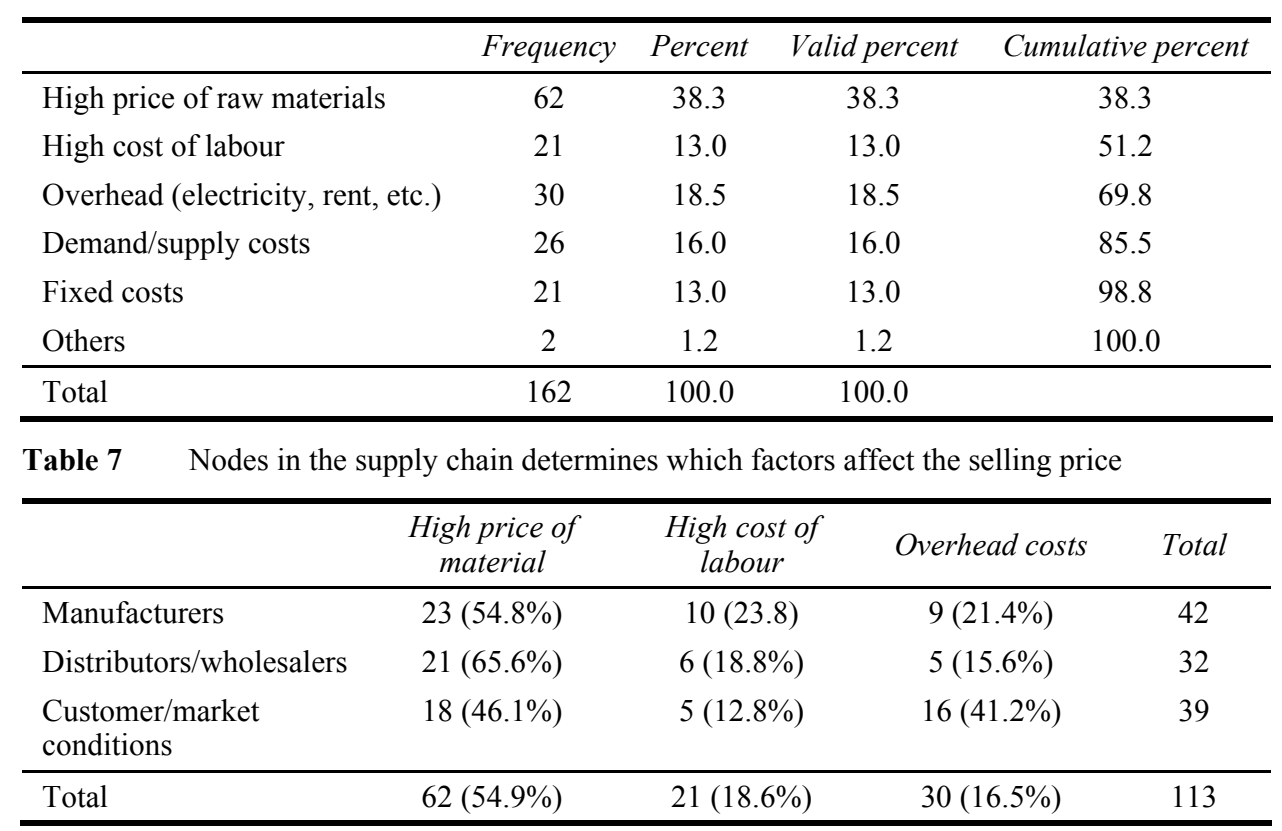


The place of products and commodities stocked, which refers to inventory, encompass all raw materials, work in process, and finished goods within a supply chain. Under this variable, 132 entrepreneurs commented that they receive the right quantity of materials as ordered from their supplier, while 30 of them said that they do not. These entrepreneurs also described their level of customer service. From the 162 entrepreneurs, 88 entrepreneurs $(54.32 \%)$ said that they have a very good customer service level of $85 \%$ and above, 62 entrepreneurs (38.27\%) stated that they have a good customer service of $70 \%$ to $84 \%$, and 12 entrepreneurs $(7.41 \%)$ declared that they have an average customer service of $50 \%$ to $69 \%$. The following factors hinder SMEs from having enough quantity of products to meet the customer orders:

1 late stock delivery was mentioned by 89 entrepreneurs

2 limited capital, which prevents entrepreneurs from purchasing products in large quantity, was ranked by 45 entrepreneurs

3 lack of business knowledge was ranked by 13 entrepreneurs

4 limited storage space was ranked by 6 entrepreneurs

5 nine entrepreneurs did not comment.

Table 8 provides a summary of information on the factors that hinder meeting the predetermined customer service level. A thorough analysis after cross tabulation of the effects of quantity towards development and growth of SMEs and the factors that hinder having enough quantity of products to be sold to customers is done (refer Table 9).

Further statistical test gave a chi-square $=9,038, p$-value $=6.0 \%>\alpha=5 \%$. These tables show that there is no significant relationship between them. Thus, revenue, business growth and service delivery are not affected by late stock delivery and limited capital. Hence, although limited capital is among the factors that hinder SMEs from having enough quantity of materials, late stock delivery is the major limiting factor. Minor factors include lack of business knowledge and limited storage space. However, these factors do not affect the revenue, business growth and service delivery of SMEs (see Figure 4 for a review of the conceptual framework's evidence).

Table 8 Summary of factors that hinder meeting the predetermined customer service

\begin{tabular}{lcccc}
\hline & Frequency & Percent & Valid percent & Cumulative percent \\
\hline Late stock delivery & 89 & 54.9 & 54.9 & 54.9 \\
Limited capital & 45 & 27.8 & 27.8 & 82.7 \\
Lack business knowledge & 13 & 8.0 & 8.0 & 90.7 \\
Limited space & 6 & 3.7 & 3.7 & 94.4 \\
Neutral & 9 & 5.6 & 5.6 & 100.0 \\
\hline Total & 162 & 100.0 & 100.0 & \\
\hline
\end{tabular}

Table 9 What are the effects of quantity towards the development of your business

\begin{tabular}{lcccc}
\hline & Late stock delivery & Limited capital & Others & Total \\
\hline Revenue & $37(71.2 \%)$ & $11(21.2 \%)$ & $4(7.6 \%)$ & $52(100 \%)$ \\
Business growth & $21(47.7 \%)$ & $13(29.5 \%)$ & $10(22.7 \%)$ & $44(100 \%)$ \\
Service delivery & $31(47.0 \%)$ & $21(31.8 \%)$ & $14(21.1 \%)$ & $66(100 \%)$ \\
\hline & $89(54.9 \%)$ & $45(27.8)$ & $28(17.3 \%)$ & $162(100 \%)$ \\
\hline
\end{tabular}


Figure 4 Proven relationship within the framework (see online version for colours)

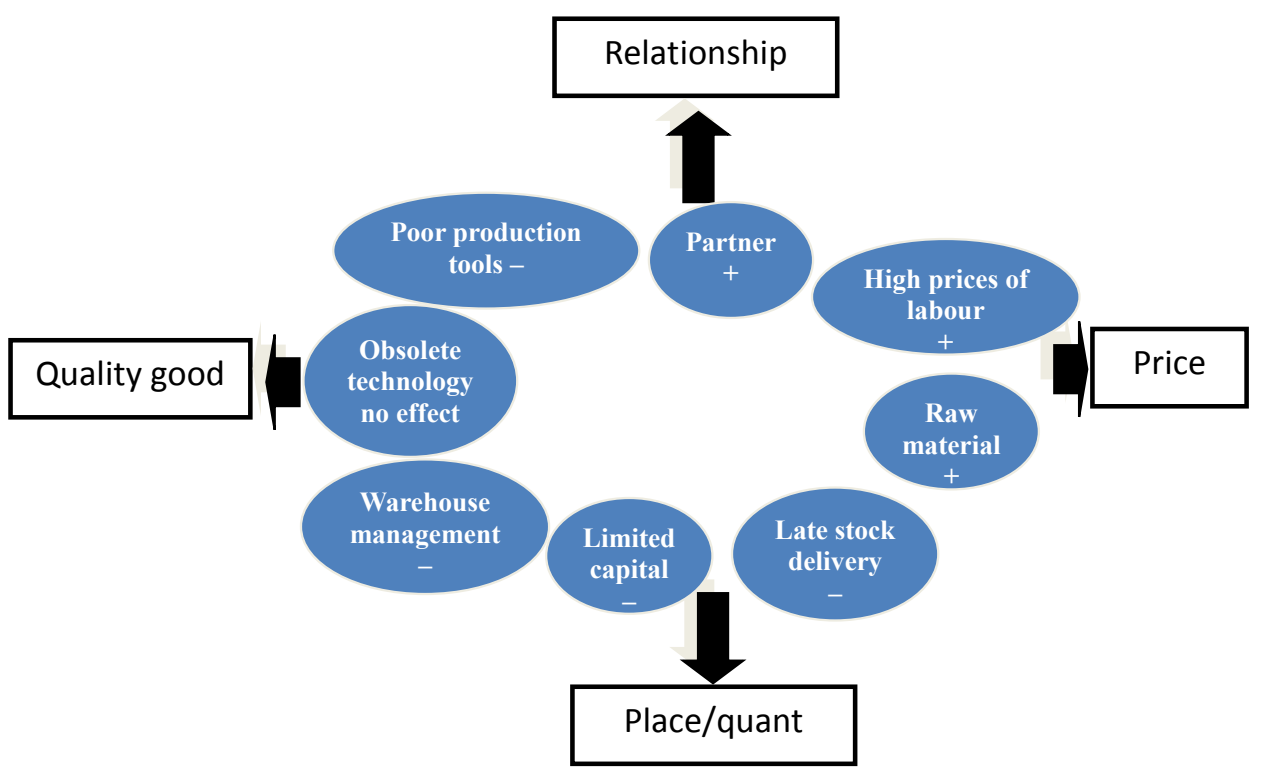

\section{Conclusions and propositions}

Based on our results, our first conclusion is that many factors hinder the contribution of purchasing variables to the development and growth of SMEs and those SMEs need to exert more effort than they are currently doing in order to overcome these obstacles. In our study we found that although most investigated SMEs (124) have a good relationship with other actors in the supply chain, 38 SMEs have an adversarial win-lose relationship. In this type of relationship, SMEs do not receive items of assured quality and quantity, purchase items at higher prices even if they are not standard, and may not receive their purchased items on time. To surmount these problems, SMEs decide to multisource from different suppliers, but this action does not improve their profits/revenue. In short, poor relationships among the supply chain members result in total disintegration of the chain and poor service to customers. To avoid this scenario, SMEs should create a win-win scenario where manufacturers and retailers work together to create highly satisfying experiences for the consumer (Srikantha Dath et al., 2008). Such a scenario would improve the performance of SMEs but also the overall supply chain. Hence, supply chain members should skip adversarial relationships and come up with collaborative relationships that can improve the performance of SMEs and the overall supply chain.

Our second conclusion is that the right quality is one of key objectives of purchasing variables. It is cross-function by nature and involves the entire organisation (Schroeder, 2004). Availability of low quality goods is one of the four factors causing underperforming SME's. Availability of low quality goods one caused by four factors. The most important of these factors are poor production tools and bad administration (also in the operation of the warehouse). The increase in variety of products and the decrease in the life cycle of products make the situation more difficult for the SMEs. 
Since SMEs sell products to end customers, they are the first ones affected by poor production since customers will not buy low quality goods. This will result in lower customer turnover, loss of goodwill, loss of sales and loss of revenue. In the end, however, the entire supply chain will be affected since even SMEs will not be interested in buying such goods from their suppliers.

Our third conclusion is that the right price is intrinsic to a successful selling transaction of an SME. The even higher costs of raw materials influence the cost of finished goods significantly. On the other hand, high costs of labour and overhead influence the cost of finished goods significantly.

Our fourth conclusion is that the right place (quantity and delivery time) is important as urgent delivery may require fast means of transport that will directly affect the final price of items that the end customer pays. Subsequently, excellent delivery performance is only an 'order winner' if the supplier can offer a competitive price, or if its delivery performance far exceeds the competitors. On the other hand, from a buyer's point of view, paying a high-price premium to receive better delivery is probably not worthwhile since the cost of holding safety stock is often dwarfed by the purchasing cost $(\mathrm{Hu}$ and Munson, 2007). Limited capital and late stock delivery also significantly influence delivery.

In the literature review, SMEs are important for the economy of Tanzania and the goal of purchasing is to ensure that the organisation acquires materials of the right quality for the right price in the right quantity at the right place. To reach this goal, SMEs must do the following:

Proposition 1 Ensure a good relationship with suppliers. For each of the individual rights, purchasing managers must make a trade-off between them. The combined impact of these rights then determines the contribution of purchasing towards development and growth of SMEs in Tanzania.

Proposition 2 Four factors affect the selling prices of products sold by SMEs where high prices of materials from actors in the supply chain have a higher impact compared to other actors. However, none of those factors directly affects other actors in the supply chain.

Hence, we recommend that SMEs find an alternative cheap source of products/commodities. Moreover, since suppliers usually offer quantity discounts to encourage the buyers to order more (Saen and Zohrehbandian, 2008), SMEs are advised to buy in large quantities so as to enjoy quantity discounts that will enable them to sell their commodities/products for low prices. Fast delivery from the manufacturers is not realistic because the infrastructure in Tanzania is not good. However, a good supply of goods will motivate more customers to buy goods that will result in generating revenue and thus in the development and growth of SMEs and the entire supply chain.

Proposition 3 The SME has to take the following steps: To begin by determining the right supplier that can deliver the right quality of materials to be purchased. Then the right quantity of goods needs to be considered. The quantity cannot be too low to cause frequent stock out or too high to cause overstocking and tie up the working capital. SMEs have to find the right supply source that will enable them to acquire materials at the right price. Thus, pricing of the materials greatly depends on other rights and costs paid by the suppliers when acquiring such products. Buying in 
large quantities results in quantity discounts while small lots do not. Hence, manufacturers and wholesalers should improve the warehouse management and administration to maintain the quality of their products. They also have to do away with obsolete production tools and hardware and look for new ones to best produce their products. Otherwise, low quality goods will continue to create a bad image for them in the market, especially to customers who value standard products. For example, industrial goods sold by entrepreneurs, especially fake Indian and Chinese electronic equipment, have short life cycles compared to the ones imported from Japan, England and Germany, according to expert opinions. These fakes have led to many customer complaints and cancellation of orders. Such decisions negatively impact on SME's development and growth and the entire supply chain performance. In cases like this, SMEs and suppliers have to be careful when ordering their products from their suppliers because they need to ensure quality goods for their customers. Failure to do so will end up in the collapse of the SME. SMEs can ensure good quality products by correctly specifying requirements and, if possible, inspecting the received goods to avoid low quality goods.

Hence, SMEs should try to balance all the four positive factors to achieve their goals of profit maximisation as well as growth and development. Moreover, since jobs created by SME's have halved unemployment (Lisotchkina, 2006; Rousek, 2006), SME's have to strive hard to keep surviving in their working environment so that they may grow and become large enterprises that employ more people.

\section{Discussion}

With regard hypothesis four, limited capital may or may not hinder SMEs in having enough quantity of products to satisfy customer orders. On the one hand, by having the right quantity of items needed by end customers, SMEs will be in a position to serve customers however they want. On the other hand, though, SMEs may have a high quantity of items that are not the right ones.

In this situation, SMEs are not in a position to offer products to end customers as required. Hence, they will end up providing poor customer service. The decision whether to keep a high level of stock is complicated by the increase in product variety; keeping each variety in inventory will tie up money in stock. By not keeping each variety in inventory will mean frequently ordering new stock. Due to this complexity, entrepreneurs are advised to make available (timely delivery) whatever is needed by end customers but not to stock everything needed by customers. This can be achieved by answering the inventory questions of what to order, when to order and how much to order. In addition, SMEs will have advantages of having enough quantity of materials that include meeting customer orders, efficient and quick service delivery. These factors will generate revenues, growth and expansion of business. On the other hand, insufficient quantity of stock may lead to poor service delivery, loss of sales, loss of customers and poor reputation to customers. 


\section{References}

Aikaeli, J. (2007) 'Improving competitiveness for SMEs to harness available trade and investment opportunities: the case of Tanzania', available at http://www.http://ssrn.com (accessed on 26 October 2008).

Andersen, P.H. and Christensen, P.R. (2005) 'Bridges over troubled water: suppliers as connective nodes in global supply networks', Journal of Business Research, September, Vol. 58, No. 9, pp.1261-1273.

Baily, P. et al. (2005) Purchasing Principles and Management, 9th ed., England Pearson Education Limited, Harlow.

Bowersox, D. and Closs, D. (1996) Logistical Management, The Integrated Supply Chain Process, McGraw-Hill, New York.

Crocker, B. and Emmett, S. (2006) The Relationship Driven Supply Chain: Creating a Culture of Collaboration through the Chain, 1st ed., Gower Publishing Company, Hampshire, England.

De Boer, L., Holmen, E. and Pop-Sitar, C. (2003) 'Purchasing as an organizational design problem: the case of non-product-related items and services', Journal of Management Decision, November, Vol. 41, No. 9, pp.911-922.

Dobler, W.D. and Burt, N.D. (1997) Purchasing and Supply Management: Text and Cases, 6th ed., Tata McGraw Hill Publishing Company, New Delhi.

Duister, G.M., Heimerik, K. and Jurriëns, J.A. (2004) 'An integrated perspective on alliance management', Journal on Chain and network Science, Vol. 18, No. 1, pp.67-89.

Easterby-Smith, M.R., Thorpe, M. and Lowe, A. (1991) Management Research: An Introduction, SAGE Publications Ltd., 6 Bonhill Street, London.

Fung, P. (1999) 'Managing purchasing in a supply chain context-evolution and resolution', Logistics and Information Management Journal, Vol. 12, No. 5, pp.362-367, available at http://xtra.emeraldinsight.com (accessed on 12 May 2009).

$\mathrm{Hu}$, J. and Munson, C.L. (2007) 'Speed versus reliability trade-offs in supplier selection', International Journal of Procurement Management, Vol. 1, Nos. 1/2, pp.238-259.

Indarti, N. and Langenberg, M. (2004) 'Factors affecting business success among SMEs: empirical evidences from Indonesia', Presented at The Second Bi-annual European Summer University, 19-21 September, University of Twente, Enschede, The Netherlands.

Kukalis, S. (1989) 'The relationship among firm characteristics and design of strategic planning systems in large organizations', Journal of Management, Vol. 15, No. 4, pp.565-579.

Lambert, D. and Cooper, M. (2000) 'Issues in supply chain management', Industrial Marketing Management, Vol. 29, No. 1, pp.65-83.

Lisotchkina, T.V. (2006) 'Investment and innovation activities of enterprises under the conditions of market economy', Int. J. Entrepreneurship and Innovation Management, Vol. 6, Nos. 1/2, pp.24-32.

Lysons, K. and Farrington, B. (2006) Purchasing and Supply Chain Management, 7th ed., Pearson Education Limited, Harlow, England.

Lysons, K. and Gillingham, M. (2003) Purchasing and Supply Chain Management, 6th ed., Pearson Education Limited, Harlow, England.

Manoilova, T. (2006) 'Problems in small- and medium-sized enterprise development in Bulgaria', International Journal of Entrepreneurship and Innovation Management, Vol. 6, Nos. 1/2, pp.33-52.

Merminod, N., Paché, G. and Calvi, R. (2007) 'The three paradoxes of supply chain management: illustrations and managerial implications', International Journal of Procurement Management, Vol. 1, Nos. 1/2, pp.60-78.

Olomi, D.R. (2006) African Entrepreneurship and Small Business Development, DUP, Dar es Salaam.

Porter, M.E. (1985) Competitive Advantage, The Free Press, New York. 
Quayle, M. and Quayle, S. (2000) 'The impact of strategic procurement in the UK further and higher education sectors', International Journal of Public Sector Management, June, Vol. 13, No. 3, pp.260-284.

Rousek, J. (2006) 'Small and medium enterprises' experience in Slovakia', Int. J. Entrepreneurship and Innovation Management, Vol. 6, Nos. 1/2, pp.89-92.

Saen, R.F. and Zohrehbandian, M. (2008) 'A data envelopment analysis approach to supplier selection in volume discount environments', International Journal of Procurement Management, Vol. 1, No. 4, pp.472-488.

Schroeder, R.G. (2004) Operations Management: Contemporary Concepts and Cases, 2nd ed., McGraw Hill Irwin, New York, NY.

Seth, J.N. and Sharma, A. (1997) 'Supplier relationships. Emerging issues and challenges', Industrial Marketing Management, Vol. 26, No. 2, pp.91-100.

Srikantha Dath, T.N., Rajendran, C. and Narashiman, K. (2008) 'A study on supply chain management from the retailer's perspective', International Journal of Procurement Management, Vol. 1, No. 4, pp.453-471.

United Republic of Tanzania (URT) (2003) Ministry of Industry and Trade, Small and Medium Enterprise Development Policy.

van der Veen, J.A.A. and Robben, H.J.S. (1999) Demand \& Supply Chain Management, Nijenrode, Breukelen, the Netherlands.

van der Vorst, J.G.A.J. (2004) 'Supply chain management: theory and practice', in The emerging World of Chains and Networks: Bridging Theory and Practice, pp.35-45, Reed Business Information, The Hague. 